\title{
Bactérias promotoras de crescimento e adubação nitrogenada no crescimento inicial de cana-de-açúcar proveniente de mudas pré-brotadas
}

\author{
Lucas Augusto da Silva Gírio(1), Fábio Luis Ferreira Dias(2), Veronica Massena Reis ${ }^{(3)}$, Segundo Urquiaga( ${ }^{(3)}$, \\ Nivaldo Schultz ${ }^{(3)}$, Denizart Bolonhezi(4) e Miguel Angelo Mutton ${ }^{(1)}$
}

\begin{abstract}
(1)Universidade Estadual Paulista, Departamento de Produção Vegetal, Via de Acesso Prof. Paulo Donato Castellani, CEP 14884-900 Jaboticabal, SP, Brasil. E-mail: lucas_girio@hotmail.com, miguelmutton@fcav.unesp.br (2)Agência Paulista de Tecnologia dos Agronegócios (Apta), Polo Centro Sul, CEP 13400-970 Piracicaba, SP, Brasil. E-mail: fabio@apta.sp.gov.br (3)Embrapa Agrobiologia, BR 465, Km 7, CEP 23890-000 Seropédica, RJ, Brasil. E-mail: veronica.massena@embrapa.br, segundo.urquiaga@embrapa.br, nsufrrj@yahoo.com.br (4)Apta, Polo Regional Centro Leste, CEP 14030-670 Ribeirão Preto, SP, Brasil. E-mail: denizart@apta.sp.gov.br
\end{abstract}

Resumo - O objetivo deste trabalho foi avaliar os efeitos da inoculação de bactérias promotoras de crescimento sobre a formação de mudas pré-brotadas de cana-de-açúcar, oriundas de gemas individualizadas, e quantificar o crescimento inicial dessas mudas, em associação à aplicação de nitrogênio, em solo de baixa fertilidade. Foram conduzidos dois experimentos: um em casa de vegetação, com duração de 50 dias, e o outro, em vasos no campo, com duração de 180 dias. Em ambos os experimentos, utilizou-se o delineamento de blocos ao acaso, em arranjo fatorial $2 \times 3$, no primeiro experimento - com ou sem inoculante, e com três quantidades de reserva nas gemas -, e $2 \times 2 \times 4$, no segundo - com ou sem inoculante, com ou sem nitrogênio, avaliados em quatro épocas: aos 45, 90, 135 e 180 dias. O inoculante produziu efeito na fase inicial de crescimento das mudas pré-brotadas, com aumento na velocidade de brotação e no acúmulo da matéria seca de raízes e da parte aérea, independentemente da quantidade de reserva da gema. No segundo experimento, o inoculante promoveu ganhos no crescimento inicial da parte aérea e do sistema radicular, até os 180 dias após o transplantio, com aumento em altura, perfilhamento, diâmetro do colmo, produção da matéria seca de colmos e de palha e do comprimento radicular, independentemente da aplicação de nitrogênio. $\mathrm{O}$ inoculante tem efeito fisiológico positivo sobre o crescimento das plantas.

Termos para indexação: Saccharum, bactérias diazotróficas, biofertilizante, fitormônios, fixação biológica de nitrogênio.

\section{Plant growth-promoting bacteria and nitrogen fertilization effect on the initial growth of sugarcane from pre-sprouted seedlings}

\begin{abstract}
The objective of this work was to evaluate the effects of the inoculation with plant growth-promoting bacteria on the formation of sugarcane pre-sprouted seedlings, originated from individual buds, and to quantify the initial growth of these seedlings in association with nitrogen application, in a low fertility soil. Two experiments were carried out: one in greenhouse conditions, with a time span of 50 days, and the other in vases under field conditions, with a time span of 180 days. In both experiments, a randomized complete block design was used with a factorial arrangement of $2 \times 3$, in the first experiment - with or without inoculation, and with three quantities of bud reserve -, and of $2 \times 2 \times 4$, in the second one - with or without inoculation, with or without nitrogen, evaluated in four times: at 45, 90, 135, and 180 days. The inoculant had effect on the initial growth of the pre-sprouted seedlings, increasing sprouting speed and dry matter accumulation on roots and shoots, regardless of the bud reserve amount. In the second experiment, the inoculant increased the initial growth of shoots and root system up to 180 days after transplantation, increasing height, tillering, stalk diameter, dry matter production of stalks and straw, and root length, regardless of nitrogen application. The inoculant has a positive physiological effect on plant growth.
\end{abstract}

Index terms: Saccharum, diazotrophic bacteria, biofertilizer, phytohormones, biological nitrogen fixation.

\section{Introdução}

Planos estratégicos, como o de Agricultura de Baixo Carbono, que contempla a fixação biológica de nitrogênio $(\mathrm{FBN})$ por bactérias promotoras de crescimento (BPC) em um dos seus programas (Plano setorial de mitigação e de adaptação às mudanças climáticas para a consolidação de uma economia de 
baixa emissão de carbono na agricultura, 2012), são importantes para o desenvolvimento, no Brasil, de uma agricultura de menor impacto e mais sustentável.

Há evidências de que o uso de biofertilizante à base de BPC pode substituir, total ou parcialmente, o uso de fertilizante nitrogenado em cana-de-açúcar (Saccharum spp. L.). Pereira et al. (2013) constataram que algumas variedades, quando inoculadas, chegam a acumular mais matéria seca do que em tratamentos com uso de fertilizante nitrogenado. Gosal et al. (2012), no entanto, relataram que o uso de inoculante na espécie permite maior acúmulo de biomassa apenas quando combinado com a adubação nitrogenada.

Segundo Pedraza (2008), além de contribuir na fixação biológica de nitrogênio, a associação com BPC em cana-de-açúcar pode reduzir o uso de fertilizantes na cultura, por solubilizar fosfatos e zinco (Saravanan et al., 2007; Estrada et al., 2013) e produzir sideróforos e reguladores de crescimento, como auxinas, giberelinas e citocininas (Lin et al., 2012; Santi et al., 2013). Alguns gêneros de BPC, como Azospirillum, favorecem o crescimento vegetal, principalmente pela síntese de auxinas (Santi et al., 2013).

Assim como na adubação nitrogenada, as respostas à inoculação dependem da variedade utilizada (Schultz et al., 2012; Urquiaga et al., 2012) e costumam ser mais frequentes em solos de média e baixa fertilidade (Oliveira et al., 2006; Gosal et al., 2012).

$\mathrm{O}$ cultivo da cana-de-açúcar com mudas pré-brotadas (Landell et al., 2012) tem permitido a redução do volume gasto de colmos por hectare; o aumento da taxa de multiplicação, da sanidade das mudas e da uniformidade do plantio; e o uso de um menor volume de material no campo, com aumento na operacionalidade do plantio. Contudo, por ter sido proposto há pouco tempo, o número de trabalhos com essa nova tecnologia ainda é escasso, especialmente quanto ao comportamento dessas mudas frente à inoculação com BPC.

O objetivo deste trabalho foi avaliar os efeitos da inoculação de bactérias promotoras de crescimento sobre a formação de mudas pré-brotadas de cana-de-açúcar, oriundas de gemas individualizadas, e quantificar o crescimento inicial dessas mudas, em associação à aplicação de nitrogênio, em solo de baixa fertilidade.

\section{Material e Métodos}

A pesquisa foi desenvolvida em área experimental pertencente à Agência Paulista de Tecnologia dos Agronegócios, Apta Polo Centro Sul, em Piracicaba, SP (22 $42^{\prime} 30^{\prime \prime} \mathrm{S}, 4^{\circ} 38^{\prime} 00^{\prime \prime} \mathrm{W}$, a $560 \mathrm{~m}$ de altitude). Foram realizados dois experimentos: um em casa de vegetação, em tubetes distribuídos em bandejas, iniciado em 22/2/2013, com duração de 50 dias (experimento 1); e outro em vasos de $130 \mathrm{~L}$, dispostos no campo (céu aberto), iniciado em 12/4/2013, com duração de 180 dias (experimento 2). Em ambos os experimentos, utilizou-se a cultivar RB 867515, pelo fato desta responder à inoculação com BPC (Schultz et al., 2012; Pereira et al., 2013) e por ser a mais cultivada no Estado de São Paulo e no Brasil (Chapola et al., 2013).

No experimento 1, utilizou-se o delineamento de blocos ao acaso, com quatro repetições, em arranjo fatorial 2x3: com ou sem inoculante, e com três níveis de reserva nas gemas $(1,5,3,0$ e 4,5 g de matéria seca por gema).

As mudas foram obtidas pelo sistema de multiplicação de mudas pré-brotadas (MPB), sugerido por Landell et al. (2012). Elas foram dispostas em 240 tubetes de $180 \mathrm{~cm}^{3}$, preenchidos com substrato da marca Basaplant, com as seguintes características químicas: $\mathrm{pH} 5,8 ; 5,9 \mathrm{~g} \mathrm{~kg}^{-1}$ de $\mathrm{N} ; 2,6 \mathrm{~g} \mathrm{~kg}^{-1}$ de $\mathrm{P}_{2} \mathrm{O}_{5}$, 2,1 $\mathrm{g} \mathrm{kg}^{-1}$ de $\mathrm{K}_{2} \mathrm{O} ; 11,6 \mathrm{~g} \mathrm{~kg}^{-1}$ de $\mathrm{CaO} ; 8,1 \mathrm{~g} \mathrm{~kg}^{-1}$ de $\mathrm{MgO} ; 2,0 \mathrm{~g} \mathrm{~kg}^{-1}$ de $\mathrm{S}$; e relação $\mathrm{C}: \mathrm{N}$ de 59:1. Cada parcela foi composta por dez tubetes.

Uma mistura com cinco espécies de BPC (Gluconacetobacter diazotrophicus, Azospirillum amazonense, Burkholderia tropica, Herbaspirillum seropedicae e $H$. rubrisubalbicans) foi utilizada, em meio turfoso (Schultz et al., 2012), para inocular as gemas, extraídas na forma de minirrebolos (segmentos de colmos com gemas individualizadas). A suspensão foi preparada com 12,5 g de turfa em $5 \mathrm{~L}$ de água, com $10^{8}$ unidades formadoras de colônia (UFC), de cada bactéria, por grama de turfa. As gemas foram imersas por cerca de 1 hora nessa suspensão (Reis et al., 2009), e as que não receberam inoculação foram imersas em água. Os minirrebolos foram plantados nos tubetes e levados à casa de vegetação, onde foram submetidos a irrigações com lâminas diárias de $15 \mathrm{~mm}$.

A brotação foi avaliada diariamente, e, com os valores contabilizados, foi calculado o índice de velocidade de germinação de Maguire (1962), aqui denominado de 
índice de velocidade de brotação (IVB), conforme a seguinte equação: IVB $=\left(\mathrm{B}_{1} / \mathrm{N}_{1}+\mathrm{B}_{2} / \mathrm{N}_{2}+\mathrm{B}_{3} / \mathrm{N}_{3}+\ldots+\mathrm{B}_{\mathrm{n}} /\right.$ $\mathrm{N}_{\mathrm{n}}$ ), em que $\mathrm{B}_{\mathrm{n}}$ é o número de brotações computadas nas " $n$ " contagens e $\mathrm{N}_{\mathrm{n}}$ é o número de dias do plantio das gemas até as " $n$ " contagens.

Ao final do experimento, as mudas foram retiradas dos tubetes, e as raízes foram lavadas em água corrente sobre peneiras com malha de $1 \mathrm{~mm}$, para remoção do substrato. $\mathrm{O}$ sistema radicular e a parte aérea foram separados, secados em estufa a $65^{\circ} \mathrm{C}$, até massa constante, e pesados em balança semianalítica, para determinação da massa de matéria seca ( $\mathrm{g}$ ) das raízes (MSR) e da parte aérea (MSPA). A massa de matéria seca total (MST) foi obtida pela soma da MSR com a MSPA.

Para o experimento 2, o delineamento utilizado também foi o de blocos ao acaso, com quatro repetições, mas no arranjo fatorial $2 \times 2 \times 4$ : com ou sem inoculante; com ou sem adubação nitrogenada (0 e $50 \mathrm{~kg} \mathrm{ha}^{-1}$ de $\mathrm{N}$ ); e com quatro épocas de avaliação, aos 45, 90, 135 e 180 dias após o transplantio.

Foram utilizados 64 vasos (parcelas), com dimensões de $0,60 \mathrm{~m}$ de diâmetro e $0,45 \mathrm{~m}$ de altura, preenchidos com uma camada de $10 \mathrm{~cm}$ de brita zero, manta acrílica e $96 \mathrm{~kg}$ de solo de baixa fertilidade, classificado como Neossolo Quartzarênico órtico (Santos et al., 2006), com as seguintes características químicas: $\mathrm{pH}$ 5,0 $\left(\mathrm{em} \mathrm{CaCl}_{2}\right) ; 2,0 \mathrm{~g} \mathrm{dm}^{-3}$ de matéria orgânica (MO); 3,0 $\mathrm{mg} \mathrm{dm}^{-3}$ de $\mathrm{P}$ (resina); 0,1, 4,0 e 1,0 $\mathrm{mmol}_{\mathrm{c}} \mathrm{dm}^{-3}$ de $\mathrm{K}, \mathrm{Ca}$ e $\mathrm{Mg}$, respectivamente; $11 \mathrm{mg} \mathrm{dm}^{-3}$ de $\mathrm{S}$ na forma de $\mathrm{SO}_{4}^{-2}$; capacidade de troca catiônica (CTC) de $17 \mathrm{mmol}_{\mathrm{c}} \mathrm{dm}^{-3}$; V de 30\%; e composição granulométrica com 915, 16 e $69 \mathrm{~g} \mathrm{~kg}^{-1}$ de areia, silte e argila, respectivamente. Os vasos foram dispostos em área nivelada, com aproximadamente $80 \mathrm{~m}^{2}$, ao ar livre e não sujeita a sombreamento

Os dados meteorológicos foram coletados na estação meteorológica automática da Apta Polo Centro Sul, localizada a $25 \mathrm{~m}$ de distância do experimento. $\mathrm{O}$ volume total de precipitação e irrigação no período de condução do experimento foi de $816,4 \mathrm{~mm}(620,2$ e 196,2 mm de chuva e irrigação, respectivamente). As médias das temperaturas máximas e mínimas, durante o período, foram de 27,3 e $13,5^{\circ} \mathrm{C}$, respectivamente.

Foi aplicado o equivalente a $418 \mathrm{~kg} \mathrm{ha}^{-1}$ de calcário (20 g por vaso), com $45 \%$ de $\mathrm{CaO}, 18 \%$ de $\mathrm{MgO}$ e poder relativo de neutralização total (PRNT) de 122\%, para elevação da saturação por bases a $60 \%$. Dois meses após a aplicação do calcário, foi feita adubação de plantio com o equivalente a $200 \mathrm{~kg} \mathrm{ha}^{-1}$ de $\mathrm{P}_{2} \mathrm{O}_{5}$ (50 $\mathrm{g}$ de superfosfato simples por vaso), metade homogeneizado em todo o solo (fosfatagem) e metade na cova de plantio da muda. Para o fornecimento de potássio, foi aplicado o equivalente a $150 \mathrm{~kg} \mathrm{ha}^{-1} \mathrm{de} \mathrm{K}_{2} \mathrm{O}$ (22,5 g de cloreto de potássio por vaso), parcelados em duas aplicações: uma na cova, no momento do plantio, e outra em cobertura, 30 dias após o transplantio (DAT). As correções e as adubações do solo foram baseadas nas recomendações de Raij et al. (1997).

Nesse experimento, as mudas foram formadas apenas com gemas de $3,0 \mathrm{~g}$. As mudas, com e sem inoculação, e com 50 dias de idade, foram transplantadas para os vasos em 12/4/2013. Dez dias após o transplantio, com as mudas já estabelecidas, foram aplicados os tratamentos com nitrogênio. Aplicaram-se, em dose única, $25 \mathrm{~g}$ de sulfato de amônio por vaso (equivalente a $50 \mathrm{~kg} \mathrm{ha}^{-1} \mathrm{de} \mathrm{N}$ ). Não houve compensação com enxofre no tratamento que não recebeu $\mathrm{N}$, em razão dos altos níveis do elemento no solo e pelo fato de a adubação fosfatada ter sido feita com superfosfato simples, que teria adicionado quantidades expressivas de $\mathrm{S}$ ao solo e diminuído a probabilidade de resposta ao nutriente.

Nas avaliações não destrutivas, realizaram-se a contagem do número de perfilhos por vaso; a medição das alturas dos perfilhos somadas ( $\Sigma$ ALT), feita da base da planta até a folha +1 (sistema de numeração de Kuijper); a somatória dos diâmetros ( $\Sigma$ DIAM), medidos na base de cada perfilho; e a estimação do índice SPAD, com o medidor Minolta SPAD-502 (Konica Minolta Sensing Americas, Inc, Ramsey, NJ, EUA) na folha +1 . A partir desses dados, foi calculada a média dos valores aferidos em cada um dos perfilhos.

Nas avaliações destrutivas, a parte aérea das plantas, em cada vaso, foi separada em colmo, folhas verdes e palha, e levada à estufa, a $65^{\circ} \mathrm{C}$, até massa constante. As partes da planta foram pesadas em balança semianalítica, para determinação da massa de matéria seca de colmos (MSC), folhas (MSF) e palha (MSP).

O sistema radicular foi separado do solo ainda no campo com auxílio de água corrente e de peneira com malha de $1,0 \mathrm{~mm}$. Os vasos foram cortados ao meio para facilitar o escoamento da água com o solo, e, posteriormente, as raízes foram lavadas no laboratório. O sistema radicular foi digitalizado por escâner de alta resolução, e as imagens geradas foram processadas 
pelo programa Safira, desenvolvido pela Embrapa Instrumentação (São Carlos, SP), tendo-se determinado o comprimento radicular, que corresponde ao somatório de todos os eixos radiculares ou ramificações. Somente após o escaneamento do sistema radicular, as raízes foram levadas à estufa a $65^{\circ} \mathrm{C}$, até massa constante, e pesadas para obter a MSR.

A MST foi determinada pela soma desta em todas as partes da planta (MSC, MSF, MSP e MSR), e a razão entre a massa de matéria seca da parte aérea e do sistema radicular (RPASR) foi calculada pela divisão entre esses componentes da planta (Lucchesi, 1984).

Os dados foram submetidos à análise de variância, a 5\% de probabilidade, e, no caso de significância dos tratamentos, as médias foram comparadas pelo teste de Tukey, a 5\% de probabilidade. O efeito da inoculação de bactérias promotoras de crescimento e da adubação nitrogenada sobre as variáveis em estudo foi avaliado ao longo do tempo por meio de regressões polinomiais. As análises estatísticas foram realizadas com o programa AgroEstat (Barbosa \& Maldonado Junior, 2010).

\section{Resultados e Discussão}

$\mathrm{Na}$ fase de formação de mudas (experimento 1), a cultivar RB 867515 mostrou-se altamente responsiva à inoculação com BPC e à quantidade de reserva nas gemas, com efeito significativo desses fatores em todas as variáveis analisadas e ausência de interação entre eles (Tabela 1).

Todos os tratamentos apresentaram 100\% de gemas brotadas, mas diferiram quanto à velocidade da brotação. O IVB, que representa a brotação média diária, foi maior nos tratamentos com inoculação (Tabela 1), o que evidencia efeito positivo das BPC sobre a brotação. Em condições de umidade e temperatura propícias à brotação, as gemas são ativadas e têm seu crescimento e desenvolvimento favorecido pela maior disponibilidade de reservas nutricionais e de fitorreguladores de crescimento (Silva et al., 2010). Portanto, como algumas bactérias promotoras de crescimento são capazes de sintetizar diferentes fitorreguladores (Santi et al., 2013), elas podem favorecer a brotação. $\mathrm{O}$ etileno, apesar de ser um hormônio pouco citado neste contexto, pode estar envolvido na aceleração da brotação, uma vez que, segundo Taiz \& Zeiger (2010), ele apresenta efeito antagônico ao das auxinas e atua sobre a quebra de dormência de gemas e sementes. Além disso, Mishra et al. (2013) verificaram que o perfilhamento da cana-de-açúcar também pode ser favorecido pelo etileno.

Ainda no experimento 1, observou-se que o maior IVB foi obtido com a maior massa de matéria seca das gemas (4,5 g) (Tabela 1). De acordo com Carneiro et al. (1995), a reserva orgânica e de $\mathrm{N}$ nos minirrebolos tem influência direta sobre a brotação e o desenvolvimento inicial das plantas. Os autores constataram, por meio de diluição isotópica, que minirrebolos com maior reserva de nitrogênio no plantio foram os que mais liberaram o nutriente para a formação do broto, com resposta positiva à brotação.

A MSR, a MSPA e a MST também foram beneficiadas pela inoculação de BPC (Tabela 1). Muthukumarasamy et al. (2006), em experimento semelhante, realizado na Índia, com as espécies bacterianas Gluconacetobacter diazotrophicus e Herbaspirillum sp., descreveram ganhos pela inoculação, tanto na biomassa de raízes quanto na parte aérea. Muñoz-Rojas \& Mellado-Caballero (2003) concluíram que os ganhos no crescimento da parte aérea das mudas de cana-de-açúcar, advindos da inoculação, dependem da variedade e da estirpe bacteriana utilizada. Marques Júnior et al. (2008) testaram o efeito da inoculação de BPC e da aplicação de ácidos húmicos sobre minirrebolos e observaram efeito positivo da inoculação sobre minirrebolos tratados termicamente. Os autores também relataram efeito benéfico da aplicação de ácidos húmicos.

Além do efeito da inoculação, a produção de MSR, MSPA e MST também foi influenciada pela quantidade de reserva nas gemas (Tabela 1). Gemas com 1,5 g de matéria seca proporcionaram os piores resultados, exceto para a MSR, em que este tratamento não diferiu do com gemas de 3,0 g. Segundo Carneiro et al. (1995), no período entre 50-60 dias após o plantio, ocorrem as maiores taxas de exportação de $\mathrm{N}$ das reservas para as brotações e, no período entre 60 70 dias, há maior degradação da reserva orgânica do minirrebolo. A maior parte do nutriente utilizado pela planta é proveniente das reservas do minirrebolo, o que explicaria as maiores produções de massa de matéria seca das mudas provenientes de gemas com maiores reservas, na fase inicial.

No experimento 2, verificou-se que o inoculante não teve efeito sobre o número de perfilhos por vaso, 
o índice SPAD (Tabela 2) ou a RPASR (Tabela 3); já a aplicação de nitrogênio proporcionou ganhos altamente significativos nessas variáveis. Observouse, no entanto, que as respostas à inoculação sofreram interação com a adubação nitrogenada (Tabelas 2 e 3).

Diversos autores (Hari \& Srinivasan, 2005; Muthukumarasamy et al., 2006; Gosal et al., 2012) mostraram que bactérias promotoras de crescimento

Tabela 1. Índice de velocidade de brotação (IVB) e produção de matéria seca de raízes (MSR), parte aérea (MSPA) e total (MST) de mudas de cana-de-açúcar (Saccharum spp.), com 50 dias de idade ${ }^{(1)}$.

\begin{tabular}{lcccc}
\hline Tratamento & IVB & MSR & $\begin{array}{c}\text { MSPA } \\
\text { (g por planta) }\end{array}$ & MST \\
\hline Sem inoculante & $0,92 \mathrm{~b}$ & $0,15 \mathrm{~b}$ & $0,50 \mathrm{~b}$ & $0,65 \mathrm{~b}$ \\
Com inoculante & $1,42 \mathrm{a}$ & $0,31 \mathrm{a}$ & $1,21 \mathrm{a}$ & $1,52 \mathrm{a}$ \\
\hline Gema com $1,5 \mathrm{~g}$ & $1,07 \mathrm{~b}$ & $0,19 \mathrm{~b}$ & $0,60 \mathrm{~b}$ & $0,80 \mathrm{~b}$ \\
Gema com 3,0 g & $1,12 \mathrm{~b}$ & $0,24 \mathrm{ab}$ & $0,90 \mathrm{a}$ & $1,14 \mathrm{a}$ \\
Gema com 4,5 g & $1,32 \mathrm{a}$ & $0,26 \mathrm{a}$ & $1,05 \mathrm{a}$ & $1,31 \mathrm{a}$ \\
\hline Inoculante $(\mathrm{I})$ & $204,17^{* *}$ & $83,41^{* *}$ & $71,58^{* *}$ & $100,44^{* *}$ \\
Gemas $(\mathrm{G})$ & $19,12^{* *}$ & $4,60^{*}$ & $9,71^{* *}$ & $11,85^{* *}$ \\
IxG & $3,52^{\text {ns }}$ & $0,22^{\text {ns }}$ & $2,19^{\text {ns }}$ & $1,79^{\text {ns }}$ \\
\hline CV $(\%)$ & 7,32 & 18,92 & 24,14 & 19,71 \\
\hline
\end{tabular}

${ }^{(1)}$ Médias seguidas de letras iguais não diferem pelo teste de Tukey, a $5 \%$ de

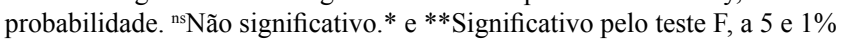
de probabilidade, respectivamente. possibilitam a redução no uso de fertilizantes. No Brasil, são observadas baixas respostas de cana-planta à adubação nitrogenada, possivelmente em razão da acentuada dinâmica da $\mathrm{MO}$ em solos tropicais e pela provável ocorrência da fixação biológica (Urquiaga et al., 2012). Como no presente estudo foi utilizado um solo arenoso, com baixo teor de $\mathrm{MO}\left(2,0 \mathrm{~g} \mathrm{dm}^{-3}\right)$, as respostas ao nitrogênio e a interação da inoculação com a adubação nitrogenada possivelmente sofreram pouca influência da MO do solo.

No desdobramento da interação entre $\mathrm{N}$ e a inoculação (Figura 1), constatou-se que, quando o inoculante esteve associado à fertilização nitrogenada, houve acréscimos significativos em todas as variáveis, em relação ao uso isolado de N. Foram observados ganhos de $12,23,15,30,17,30$ e $14 \%$, respectivamente, para número de perfilhos, somatória das alturas e dos diâmetros, comprimento de raízes, MSC, MSP e MST. Esses resultados corroboram os de Muthukumarasamy et al. (2006), que verificaram efeito benéfico da BPC sobre a produção de matéria seca total. Tanto nos tratamentos inoculados quanto nos não inoculados, a MST aumentou linearmente com o decorrer do tempo; porém, nos tratamentos inoculados, ela foi maior, e a diferença entre eles aumentou ao longo do tempo (Figura 2). Das partes da planta que compõem a matéria seca total, apenas raízes e folhas não foram

Tabela 2. Número de perfilhos, somatória das alturas e dos diâmetros, comprimento de raízes e índice SPAD de plantas de cana-de-açúcar (Saccharum spp.) cultivadas, em vasos, até os 180 dias após o transplantio (DAT) ${ }^{(1)}$.

\begin{tabular}{|c|c|c|c|c|c|}
\hline \multirow[t]{2}{*}{ Tratamentos } & \multirow[t]{2}{*}{ Perfilhos por vaso } & \multicolumn{2}{|c|}{ Somatório } & \multirow{2}{*}{$\begin{array}{l}\text { Comprimento de } \\
\text { raízes (m) }\end{array}$} & \multirow{2}{*}{$\begin{array}{l}\text { Índice } \\
\text { SPAD }\end{array}$} \\
\hline & & Altura $(\mathrm{cm})$ & Diâmetro (mm) & & \\
\hline Sem inoculante & $4,40 \mathrm{a}$ & $61,77 \mathrm{~b}$ & $48,31 \mathrm{~b}$ & $90,88 \mathrm{~b}$ & $29,98 \mathrm{a}$ \\
\hline Com inoculante & $4,56 \mathrm{a}$ & $72,70 \mathrm{a}$ & $54,34 \mathrm{a}$ & $114,96 \mathrm{a}$ & $29,37 \mathrm{a}$ \\
\hline $0 \mathrm{~kg} \mathrm{ha}^{-1}$ de $\mathrm{N}$ & $1,41 \mathrm{~b}$ & $16,67 b$ & $14,88 \mathrm{~b}$ & $25,82 b$ & $27,05 b$ \\
\hline $50 \mathrm{~kg} \mathrm{ha}^{-1}$ de N & $7,56 \mathrm{a}$ & $117,81 \mathrm{a}$ & $87,78 \mathrm{a}$ & $180,02 \mathrm{a}$ & $32,30 \mathrm{a}$ \\
\hline $45 \mathrm{DAT}$ & $2,94 b$ & $22,46 \mathrm{~d}$ & $20,50 \mathrm{~d}$ & $10,10 \mathrm{~d}$ & $39,24 a$ \\
\hline 90 DAT & $3,63 b$ & $60,36 \mathrm{c}$ & $43,56 \mathrm{c}$ & $55,19 \mathrm{c}$ & $30,11 \mathrm{~b}$ \\
\hline 135 DAT & $5,81 \mathrm{a}$ & $85,36 \mathrm{~b}$ & $64,44 \mathrm{~b}$ & $134,50 \mathrm{~b}$ & $25,98 b c$ \\
\hline $180 \mathrm{DAT}$ & $5,56 \mathrm{a}$ & $100,77 \mathrm{a}$ & $76,81 \mathrm{a}$ & $211,89 \mathrm{a}$ & $23,36 \mathrm{c}$ \\
\hline Inoculante (I) & $0,26^{\mathrm{ns}}$ & $8,46^{* *}$ & $5,27^{*}$ & $31,69 * *$ & $0,28^{\mathrm{ns}}$ \\
\hline Nitrogênio (N) & $406,05 * *$ & $724,12 * *$ & $769,41 * *$ & $1298,90 * *$ & $21,05^{* *}$ \\
\hline Época (E) & $21,63^{* *}$ & $82,71^{* *}$ & $88,40^{* *}$ & $432,76^{* *}$ & $37,06 * *$ \\
\hline $\mathrm{IxN}$ & $5,53^{*}$ & $12,22 * *$ & $5,94^{*}$ & $28,68^{* *}$ & $0,05^{\text {ns }}$ \\
\hline $\mathrm{IxE}$ & $1,57^{\mathrm{ns}}$ & $3,21^{*}$ & $1,24^{\mathrm{ns}}$ & $4,58 * *$ & $0,77^{\mathrm{ns}}$ \\
\hline $\mathrm{NxE}$ & $24,84 * *$ & $63,43^{* *}$ & $72,66^{* *}$ & $297,54 * *$ & $3,90^{*}$ \\
\hline IxNxE & $0,21^{\mathrm{ns}}$ & $1,79^{\mathrm{ns}}$ & $0,41^{\mathrm{ns}}$ & $5,64 * *$ & $0,03^{\mathrm{ns}}$ \\
\hline$\overline{\mathrm{CV}(\%)}$ & 27,25 & 22,36 & 20,48 & 16,63 & 15,41 \\
\hline
\end{tabular}

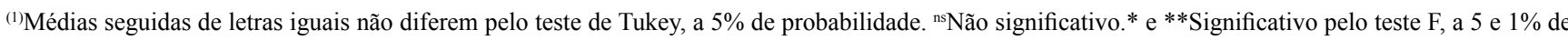
probabilidade, respectivamente. 

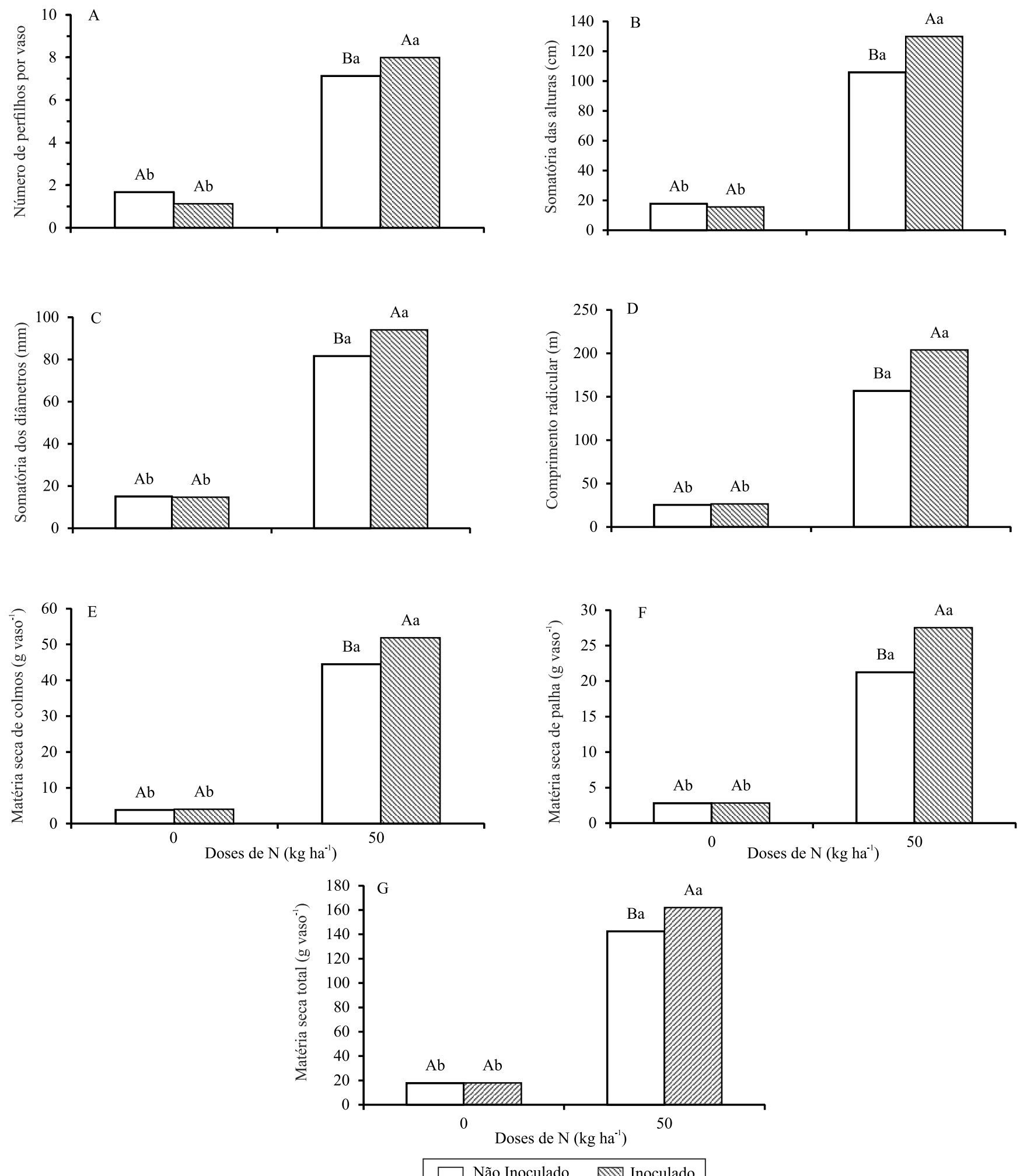

Figura 1. Desdobramento da interação entre inoculação e doses de N, quanto a: A, número de perfilhos; B, somatória das alturas; C, somatória dos diâmetros; D, comprimento radicular; E, matéria seca de colmos; F, matéria seca de palha; e G, matéria seca total. Médias seguidas de letras iguais, maiúsculas para inoculação e minúsculas para a adição de N, não diferem pelo teste de Tukey, a 5\% de probabilidade. 
favorecidas pela inoculação; a adição de nitrogênio, entretanto, promoveu respostas positivas em todas as variáveis (Tabela 3 ).

A adição de $\mathrm{N}$ promoveu ganhos crescentes até os 180 dias, ao se considerar a somatória das alturas e dos diâmetros, bem como as variáveis MSR, MSC, MSP e MST (Figuras 3 e 4). Contudo, quando a cana-de-açúcar não recebeu a dose de $50 \mathrm{~kg} \mathrm{ha}^{-1}$ de $\mathrm{N}$, as plantas apresentaram baixo desenvolvimento, e a diferença para as que receberam a adubação foi visualizada já a partir da segunda amostragem (Figuras 3 e 4).

Embora a massa do sistema radicular não tenha sido favorecida pela inoculação, é possível inferir que as bactérias promotoras de crescimento modificaram a arquitetura do sistema radicular (Hari \& Srinivasan, 2005; Gosal et al., 2012), uma vez que o comprimento radicular nos tratamentos inoculados foi maior do que nos não inoculados (Tabela 2), apesar de terem apresentado massas iguais (Tabela 3). Portanto, a inoculação proporcionou um sistema radicular mais fino, que possibilita maior superfície de contato com o solo e permite captar mais água e nutrientes (Bhattacharjee et al., 2008). Esta alteração é atribuída à síntese de hormônios que alteram a morfologia das raízes, com o aumento de raízes laterais e pelos radiculares (Okumura et al., 2013; Santi et al., 2013), e pôde ser constatada a partir da segunda avaliação (Figura 2).

Quanto à parte aérea, apenas colmos e palha responderam à inoculação, tendo-se observado interação com o fornecimento de N. De acordo com Hawkesford et al. (2012), a deficiência de $\mathrm{N}$ reduz a RPASR, pois o desenvolvimento do sistema radicular é menos prejudicado que o da parte aérea, nessa condição (Figura 4). O número de perfilhos apresentou comportamento similar ao da MSF, com crescimento até os 135 DAT e estabilização após este período. Segundo Orlando Filho \& Rodella (1995) e Simões et al. (2005), o aumento nos valores dessas variáveis após esse período é impedido pela competição entre as plantas e pelo autossombreamento.

$\mathrm{O}$ índice SPAD, que reflete teores relativos de clorofila, diminuiu ao longo do tempo, independentemente do suprimento de N (Figura 3). Esse resultado evidencia o efeito de diluição do $\mathrm{N}$ absorvido pelas plantas, em razão do maior acúmulo de matéria seca com o tempo.

Tabela 3. Razão entre a massa de matéria seca da parte aérea e do sistema radicular (RPASR), e massas de matéria seca de raízes (MSR), colmos (MSC), folhas (MSF), palha (MSP) e total (MST), em plantas de cana-de-açúcar (Saccharum spp.) cultivadas, em vasos, até os 180 dias após o transplantio (DAT) ${ }^{(1)}$.

\begin{tabular}{|c|c|c|c|c|c|c|}
\hline \multirow[t]{2}{*}{ Tratamentos } & RPASR & MSR & MSC & MSF & MSP & MST \\
\hline & & \multicolumn{5}{|c|}{ 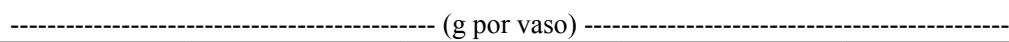 } \\
\hline Sem inoculante & $1,83 \mathrm{a}$ & $30,35 \mathrm{a}$ & $24,17 \mathrm{~b}$ & $13,60 \mathrm{a}$ & $12,03 \mathrm{~b}$ & $80,15 b$ \\
\hline Com inoculante & $1,80 \mathrm{a}$ & $31,96 \mathrm{a}$ & $27,95 \mathrm{a}$ & $14,69 \mathrm{a}$ & $15,17 \mathrm{a}$ & $89,78 \mathrm{a}$ \\
\hline $0 \mathrm{~kg} \mathrm{ha}^{-1}$ de $\mathrm{N}$ & $1,41 b$ & $7,68 b$ & $3,92 b$ & $3,38 b$ & $2,82 \mathrm{~b}$ & $17,81 \mathrm{~b}$ \\
\hline $50 \mathrm{~kg} \mathrm{ha}^{-1}$ de N & $2,22 \mathrm{a}$ & $54,63 \mathrm{a}$ & $48,20 \mathrm{a}$ & $24,90 \mathrm{a}$ & $24,38 \mathrm{a}$ & $152,12 \mathrm{a}$ \\
\hline $45 \mathrm{DAT}$ & $2,40 \mathrm{a}$ & $3,04 d$ & $3,47 \mathrm{~d}$ & $2,80 \mathrm{c}$ & $0,66 \mathrm{~d}$ & $9,96 \mathrm{~d}$ \\
\hline 90 DAT & $1,84 \mathrm{~b}$ & $16,63 \mathrm{c}$ & $21,76 \mathrm{c}$ & $8,21 b$ & $5,96 \mathrm{c}$ & $52,56 \mathrm{c}$ \\
\hline 135 DAT & $1,51 \mathrm{~b}$ & $40,71 b$ & $30,42 b$ & $21,22 \mathrm{a}$ & $15,27 b$ & $107,62 b$ \\
\hline 180 DAT & $1,51 \mathrm{~b}$ & $64,25 \mathrm{a}$ & $48,59 a$ & $24,36 \mathrm{a}$ & $32,51 \mathrm{a}$ & $169,72 \mathrm{a}$ \\
\hline Inoculante (I) & $0,09^{\text {ns }}$ & $1,38^{\mathrm{ns}}$ & $5,45^{*}$ & $1,48^{\mathrm{ns}}$ & $8,81 * *$ & $5,90 *$ \\
\hline Nitrogênio (N) & $64,76^{* *}$ & $1171,29 * *$ & $745,50 * *$ & $569,47 * *$ & $415,54 * *$ & $1147,31 * *$ \\
\hline Época $(\mathrm{E})$ & $17,17 * *$ & $387,50 * *$ & $133,83 * *$ & $130,52 * *$ & $174,70 * *$ & $304,70 * *$ \\
\hline $\mathrm{IxN}$ & $0,54^{\mathrm{ns}}$ & $1,74^{\mathrm{ns}}$ & $4,87^{*}$ & $1,80^{\mathrm{ns}}$ & $8,75^{* *}$ & $6,02 *$ \\
\hline IxE & $1,18^{\mathrm{ns}}$ & $0,19^{\text {ns }}$ & $2,16^{\mathrm{ns}}$ & $0,52^{\mathrm{ns}}$ & $1,79^{\mathrm{ns}}$ & $1,00^{\mathrm{ns}}$ \\
\hline $\mathrm{NxE}$ & $8,40 * *$ & $268,23^{* *}$ & $100,84 * *$ & $101,03 * *$ & $129,11 * *$ & $219,55^{* *}$ \\
\hline IxNxE & $0,07^{\mathrm{ns}}$ & $0,30^{\text {ns }}$ & $1,81^{\mathrm{ns}}$ & $0,90^{\mathrm{ns}}$ & $1,87^{\mathrm{ns}}$ & $1,33^{\mathrm{ns}}$ \\
\hline CV (\%) & 22,26 & 17,61 & 24,89 & 25,50 & 31,10 & 18,67 \\
\hline
\end{tabular}

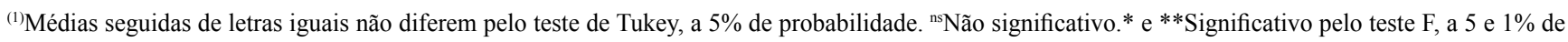
probabilidade, respectivamente. 

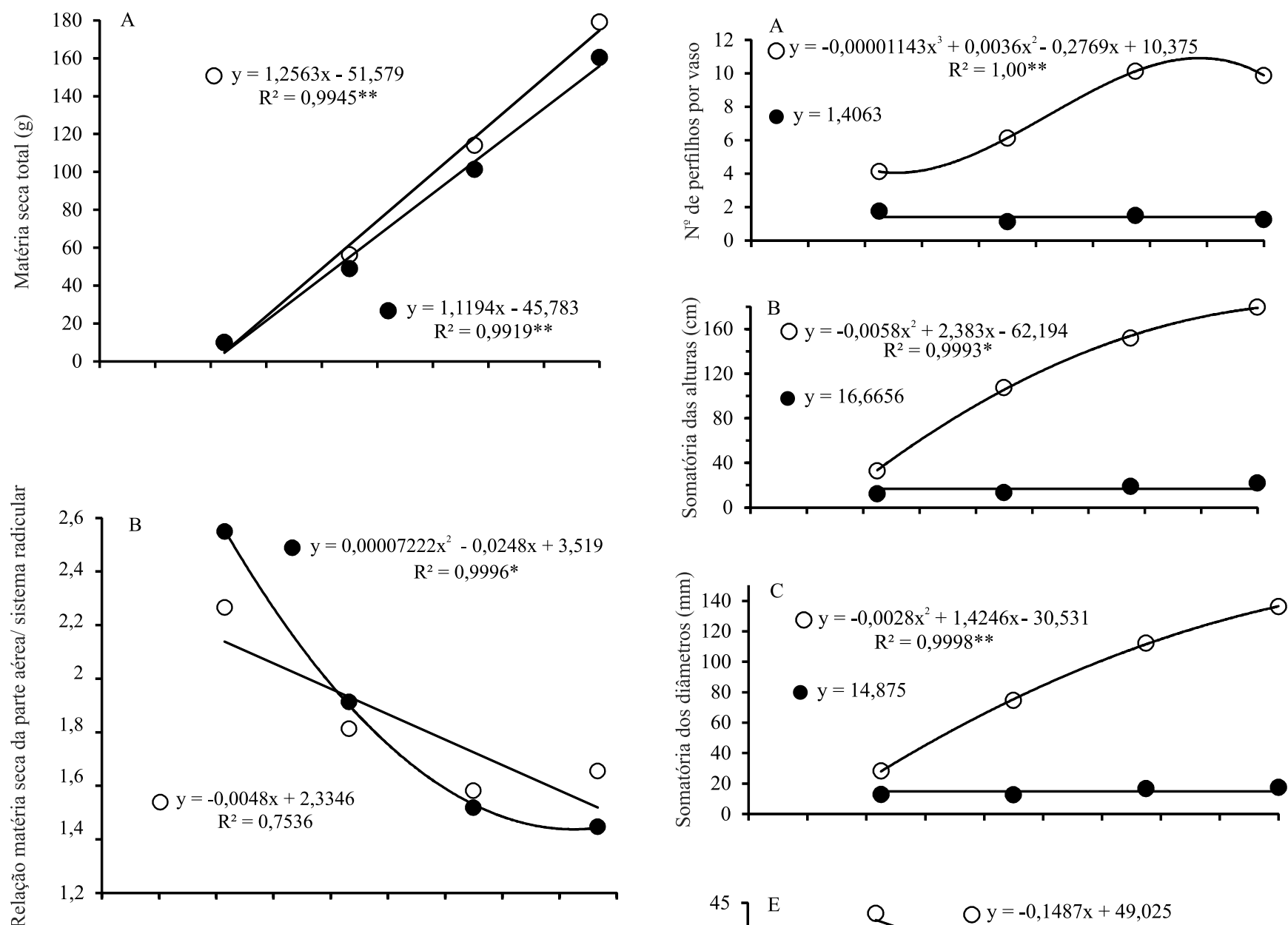

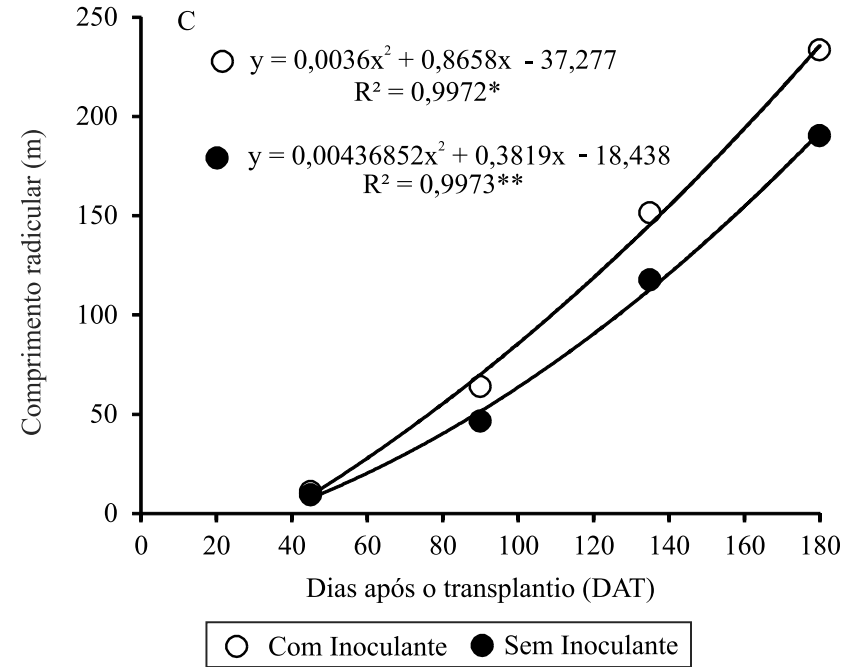

Figura 2. Produção de massa de matéria seca total (A), relação entre produção de matéria seca na parte aérea e no sistema radicular (B), e comprimento radicular (C), com e sem inoculação, em função do tempo.
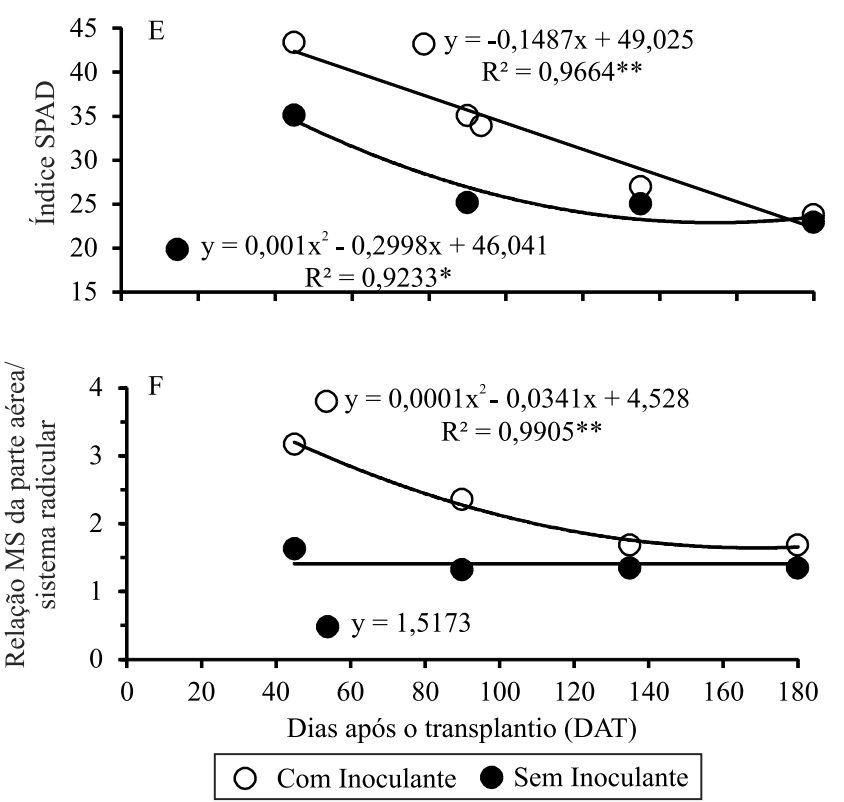

Figura 3. Número de perfilhos (A), somatória das alturas (B) e dos diâmetros (C), índice SPAD (D) e relação entre produção de matéria seca na parte aérea e no sistema radicular por vaso (E), com e sem nitrogênio, na dose de $50 \mathrm{~kg} \mathrm{ha}^{-1}$, em função do tempo. 

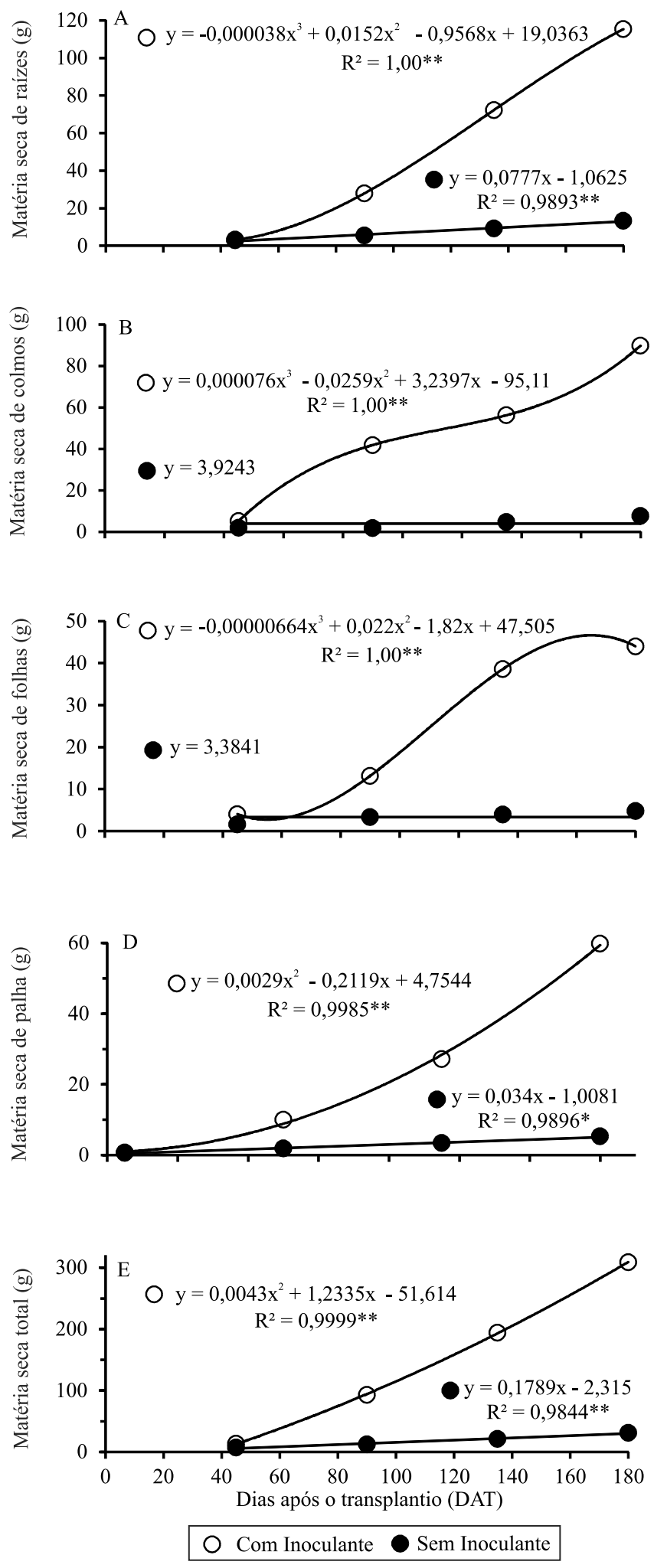

Figura 4. Massas de matéria seca de raízes (A), colmos (B), folhas (C), palha (D) e total (E) por vaso, com e sem adição de nitrogênio, na dose de $50 \mathrm{~kg} \mathrm{ha}^{-1}$, em função do tempo.

\section{Conclusões}

1. Na formação de mudas pré-brotadas da cultivar RB 867515 de cana-de-açúcar (Saccharum spp.), a inoculação aumenta a velocidade de brotação e o acúmulo de matéria seca das raízes e da parte aérea, independentemente da quantidade de reserva da gema.

2. A inoculação associada ao fornecimento de $\mathrm{N}$ favorece o crescimento inicial da parte aérea até os 180 dias após o transplantio, ao aumentar o perfilhamento, a altura, o diâmetro e a produção das matérias secas de colmos, palha e total das plantas.

3. A utilização do inoculante não aumenta a massa de matéria seca das raízes, mas promove o incremento no comprimento radicular.

4. A inoculação da cana-de-açúcar com bactérias promotoras do crescimento tem efeito fisiológico sobre o crescimento de plantas.

\section{Agradecimentos}

À Coordenação de Aperfeiçoamento de Pessoal de Nível Superior (Capes), pela concessão de bolsa; à Agência Paulista de Tecnologia dos Agronegócios (Apta), pela infraestrutura e apoio técnico; e à Embrapa Agrobiologia, pelo fornecimento do inoculante.

\section{Referências}

BARBOSA, J.C.; MALDONADO JUNIOR, W. AgroEstat: sistema para análises estatísticas de ensaios agronômicos. Versão 1.1. Jaboticabal: Departamento de Ciências Exatas, 2010.

BHATTACHARJEE, R.B.; AQBAL, S.; MUKHOPADHYAY, S.N. Use of nitrogen-fixing bacteria as biofertiliser for non-legumes: prospects and challenges. Applied Microbiology and Biotechnology, v.80, p.199-209, 2008. DOI: 10.1007/ s00253-008-1567-2.

CARNEIRO, A.E.V.; TRIVELIN, P.C.O.; VICTORIA, R.L. Utilização da reserva orgânica e de nitrogênio do tolete de plantio (colmo-semente) no desenvolvimento da cana-planta. Scientia Agricola, v.52, p.199-209, 1995. DOI: 10.1590/ S0103-90161995000200001.

CHAPOLA, R.G.; CRUZ, J.A.; NUNES, I.K.; FERNANDES JÚNIOR, A.R. Censo varietal 2012. Araras: Rede Interuniversitária para o Desenvolvimento do Setor Sucroenergético, Universidade Federal de Goiás, 2013. 55p.

ESTRADA, G.A.; BALDANI, V.L.D.; OLIVEIRA, D.M. de; URQUIAGA,S.;BALDANI,J.I.Selectionofphosphate-solubilizing diazotrophic Herbaspirillum and Burkholderia strains and their effect on rice crop yield and nutrient uptake. Plant and Soil, v.369, p.115-129, 2013. DOI: 10.1007/s11104-012-1550-7. 
GOSAL, S.K.; KALIA, A.; UPPAL, S.K.; KUMAR, R.; WALIA, S.S.; SINGH, K.; SINGH, H. Assessing the benefits of Azotobacter bacterization in sugarcane: a field appraisal. Sugar Tech, v.14, p.61-67, 2012. DOI: 10.1007/s12355-011-0131-z.

HARI, K.; SRINIVASAN, T.R. Response of sugarcane varieties to application of nitrogen fixing bacteria under different nitrogen levels. Sugar Tech, v.7, p.28-31, 2005. DOI: 10.1007/BF02942525.

HAWKESFORD, M.; HORST, W.; KICHEY, T.; LAMBERS, H.; SCHJOERRING, J.; SKRUMSAGER, I.; WHITE, P. Functions of macronutrients. In: MARSCHNER, P. (Ed.). Marschners's mineral nutrition of higher plants. Australia: The University of Adelaide: Elsevier, 2012. p.135-188. DOI: 10.1016/ B978-0-12-384905-2.00006-6.

LANDELL, M.G. de A.; CAMPANA, M.P.; FIGUEIREDO, P.; XAVIER, M.A.; ANJOS, I.A. dos; DINARDO-MIRANDA, L.L.; SCARPARI, M.S.; GARCIA, J.C.; BIDÓIA, M.A.P.; SILVA, D.N. da; MENDONÇA, J.R. de; KANTHACK, R.A.D.; CAMPOS, M.F. de; BRANCALIÃO, S.R.; PETRI, R.H.; MIGUEL P.E.M. Sistema de multiplicação de cana-de-açúcar com uso de mudas pré-brotadas (MPB), oriundas de gemas individualizadas. Ribeirão Preto: Instituto Agronômico de Campinas, 2012. 17p. (IAC. Documentos, 109).

LIN, L.; LI, Z.; HU, C.; ZHANG, X.; CHANG, S.; YANG, L.; LI, Y.; AN, Q. Plant growth-promoting nitrogen-fixing enterobacteria are in association with sugarcane plants growing in Guangxi, China. Microbes and Environments, v.27, p.391-398, 2012. DOI: 10.1264/jsme2.ME11275.

LUCCHESI, A.A. Utilização prática da análise de crescimento vegetal. Anais da Escola Superior deAgricultura Luiz de Queiroz, v.41, p.181-201, 1984. DOI: 10.1590/S0071-12761984000100011.

MAGUIRE, J.D. Speed of germination - aid in selection and evaluation for seedling emergence and vigor. Crop Science, v.2, p.176-177, 1962. DOI: 10.2135/cropsci1962.0011183X00020002 $0033 \mathrm{x}$.

MARQUES JÚNIOR, R.B.; CANELLAS, L.P.; SILVA, L.G. da; OLIVARES, F.L. Promoção de enraizamento de microtoletes de cana-de-açúcar pelo uso conjunto de substâncias húmicas e bactérias diazotróficas endofíticas. Revista Brasileira de Ciência do Solo, v.32, p.1121-1128, 2008. DOI: 10.1590/ S0100-06832008000300020.

MISHRA, S.; NAILWAL, T.K.; PANT, R.C. In vitro study of role of ethylene during tillering in sugarcane. Sugar Tech, v.16, p.255-263, 2013. DOI: 10.1007/s12355-013-0251-8.

MUÑOZ-ROJAS, J.; MELLADO-CABALLERO, J. Population dynamics of Gluconacetobacter diazotrophicus in sugarcane cultivars and its effect on plant growth. Microbial Ecology, v.46, p.454-464, 2003. DOI: 10.1007/s00248-003-0110-3.

MUTHUKUMARASAMY, R.; GOVINDARAJAN, M.; VADIVELU, M.; REVATHI, G. N-fertilizer saving by the inoculation of Gluconacetobacter diazotrophicus and Herbaspirillum sp. in micropropagated sugarcane plants. Microbiological Research, v.161, p.238-245, 2006. DOI: 10.1016/j.micres.2005.08.007.

OKUMURA, R.S.; MARIANO, D. de C.; DALLACORT, R.; ALBUQUERQUE, A.N. de; LOBATO, A.K. da S.; GUEDES, E.M.S.; OLIVEIRA NETO, C.F. de; CONCEIÇÃO, H.E.O. da;
ALVES, G.A.R. Azospirillum: a new and efficient alternative to biological nitrogen fixation in grasses. Journal of Food, Agriculture and Environment, v.11, p.1142-1146, 2013.

OLIVEIRA, A.L.M. de; CANUTO, E. de L.; URQUIAGA, S.; REIS, V.M.; BALDANI, J.I. Yield of micropropagated sugarcane varieties in different soil types following inoculation with diazotrophic bacteria. Plant and Soil, v.284, p.23-32, 2006. DOI: 10.1007/s11104-006-0025-0.

ORLANDO FILHO, J.; RODELLA, A.A. Adubação nitrogenada em cana-planta: perfilhamento e produtividade agrícola. STAB, V.13, p.16-18, 1995.

PEDRAZA, R. Recent advances in nitrogen-fixing acetic acid bacteria. International Journal of Food Microbiology, v.125, p.25-35, 2008. DOI: 10.1016/j.ijfoodmicro.2007.11.079.

PEREIRA, W.; LEITE, J.M.; HIPÓLITO, G. de S.; SANTOS, C.L.R. dos; REIS, V.M. Acúmulo de biomassa em variedades de cana-de-açúcar inoculadas com diferentes estirpes de bactérias diazotróficas. Revista Ciência Agronômica, v.44, p.363-370, 2013. DOI: 10.1590/S1806-66902013000200020.

PLANO setorial de mitigação e de adaptação às mudanças climáticas para a consolidação de uma economia de baixa emissão de carbono na agricultura. Brasília: Ministério da Agricultura Pecuária e Abastecimento, 2012. 173p.

RAIJ, B. van; CANTARELLA, H.; QUAGGIO, J.A.; FURLANI, A.M.C. Recomendações de adubação e calagem para o Estado de São Paulo. 2.ed. Campinas: Instituto Agronômico, 1997. 285p. (IAC. Boletim técnico, 100).

REIS, V.M.; PEREIRA, W.; HIPÓLITO, G. de S. Métodos de inoculação de bactérias diazotróficas em cana-planta para fins de determinação de eficiência agronômica. Seropédica: Embrapa Agrobiologia, 2009. 4p. (Embrapa Agrobiologia. Comunicado técnico, 118).

SANTI, C.; BOGUSZ, D.; FRANCHE, C. Biological nitrogen fixation in non-legume plants. Annals of Botany, v.111, p.743-767, 2013. DOI: $10.1093 / \mathrm{aob} / \mathrm{mct} 048$.

SANTOS, H.G. dos; JACOMINE, P.K.T.; ANJOS, L.H.C. dos; OLIVEIRA, V.A. de; OLIVEIRA, J.B. de; COELHO, M.R.; LUMBRERAS, J.F.; CUNHA, T.J.F. (Ed.). Sistema brasileiro de classificação de solos. 2.ed. Rio de Janeiro: Embrapa Solos, 2006. $306 \mathrm{p}$.

SARAVANAN, V.S.; MADHAIYAN, M.; THANGARAJU, M. Solubilization of zinc compounds by the diazotrophic, plant growth promoting bacterium Gluconacetobacter diazotrophicus. Chemosphere, v.66, p.1794-1798, 2007. DOI: 10.1016/j. chemosphere.2006.07.067.

SCHULTZ, N.; MORAIS, R.F. de; SILVA, J.A. da; BAPTISTA, R.B.; OLIVEIRA, R.P.; LEITE, J.M.; PEREIRA, W.; CARNEIRO JÚNIOR, J. de B.; ALVES, B.J.R.; BALDANI, J.I.; BODDEY, R.M.; URQUIAGA, S.; REIS, V.M. Avaliação agronômica de variedades de cana-de-açúcar inoculadas com bactérias diazotróficas e adubadas com nitrogênio. Pesquisa Agropecuária Brasileira, v.47, p.261-268, 2012. DOI: 10.1590/ S0100-204X2012000200015. 
SILVA, M.A.; SANTOS, C.M.; ARANTES, M.T.; PINCELLI, R.P. Fenologia da cana-de-açúcar. In: CRUSCIOL, C.A.C.; SILVA, M. de A.; ROSSETTO, R.; SORATTO, R.P. (Ed.). Tópicos em ecofisiologia da cana-de-açúcar. Botucatu: Fundação de Estudos e Pesquisas Agrícolas e Florestais, 2010. p.8-21.

SIMÕES, M.D.; ROCHA, J.V.; LAMPARELLI, R.A.C. Growth indices and productivity in sugarcane. Scientia Agricola, v.62, p.23-30, 2005. DOI: 10.1590/S0103-90162005000100005.
TAIZ, L.; ZEIGER, E. Plant physiology. Sunderland: Sinauer, 2010. 782p.

URQUIAGA, S.; XAVIER, R.P.; MORAIS, R.F. de; BATISTA, R.B.; SCHULTZ, N.; LEITE, J.M.; SÁ, J.M. e; BARBOSA, K.P.; RESENDE, A.S. de; ALVES, B.J.R.; BODDEY, R.M. Evidence from field nitrogen balance and ${ }^{15} \mathrm{~N}$ natural abundance data for the contribution of biological $\mathrm{N}_{2}$ fixation to Brazilian sugarcane varieties. Plant and Soil, v.356, p.5-21, 2012. DOI: 10.1007/ s11104-011-1016-3.

Recebido em 4 de junho de 2014 e aprovado em 16 de dezembro de 2014 